\title{
Entrepreneurial decisions: Insights into the use of support services for new business creation
}

\author{
G. Ammetller ${ }^{\mathrm{a}}$, I. Rodríguez-Ardura ${ }^{\mathrm{b}^{*}}$ and J. Lladós-Masllorens ${ }^{\mathrm{c}}$ \\ ${ }^{a}$ Internet Interdisciplinary Institute, Open University of Catalonia (Universitat Oberta de Catalunya), Barcelona, Spain \\ bBabson College, Wellesley, Massachusetts; and Internet Interdisciplinary Institute, Open University of Catalonia (Universitat Oberta de \\ Catalunya), Barcelona, Spain \\ Internet Interdisciplinary Institute, Open University of Catalonia (Universitat Oberta de Catalunya), Barcelona, Spain \\ *To whom all correspondence should be addressed \\ irodriguez@uoc.edu
}

\begin{abstract}
This research presents an integrative model about the use of those services that have been specifically designed to support entrepreneurial initiative. By contrast with conventional perspectives from the entrepreneurship field, mainly drawn from a resource-based view, we propose a two-fold approach to explain the utilization of services that are oriented to new business creation: by considering the role of resources within the start-up's reach (internal and external); by incorporating a behavioral and decision-making approach. On the basis of the suggested decision-making framework, a multi-stage decision model is developed and tested by means of a representative sample of entrepreneurs linked to a local development agency. The results show that the adoption and use of support services for new business creation is a complex and reflexive process, triggered by the entrepreneur's internal forces. The entrepreneur searches for information throughout the process and, with assistance from internal teams and external networks, evaluates the choices of businesssupport services. Our findings offer relevant implications and recommendations for business incubators and institutions.
\end{abstract}

\section{Introduction}

Business creation is a critical activity for innovation. Its impact is crucially reflected in economic growth and competitiveness. In fact, the formation of new firms is a very relevant source of an increase in job promotion and companies" productivity; this ultimately contributes to economic and social progress. But emerging businesses face situations that, when not adequately resolved, may affect their development. These situations often require advanced knowledge and capabilities, which might over-stretch a start-up's internal tangible and intangible resources (Gooderham, Tobiassen, Døving \& Nordhaug, 2004; Dyer $\&$ Ross, 2008). To address these shortcomings (Van den Ven, Hudson \& Schroeder, 1984; Peña, 2002; Chrisman \& McMullan, 2000, 2004), many start-ups turn to external Business Support Services (BSS).

BSS are usually offered by business incubators and institutions (e.g. Business Link in the UK, the Kauffman Foundation in the US, the Small Enterprise Development Agency in South Africa, the Technologie Zentrum in Germany, Barcelona Activa in Spain) who, in their attempt to facilitate innovation, competitiveness and economic development (Mole \& Bramley 2006), promote and deliver help to emerging businesses. Ranging from space incubation to networking opportunities and counseling services, BSS offer various knowledge and expertise resources (Chrisman \& McMullan, 2000; Mole \& Keogh, 2009) that start-ups might need. As a matter of fact, BSS programs often configure true collective learning environments, where entrepreneurs can acquire and transfer business knowledge and experiences, foster the exchange of business ideas, and help to develop fruitful business relationships.

A great deal of research has drawn upon the resource-based view to explain the adoption and utilization of BSS by startups. Stemming from this, some studies (for example Westhead, 1995; Kor \& Mahoney, 2000; Adler \& Kwon, 2002; Ucbasaran, Lockett, Wright \& Westhead, 2003) have examined the driving role played by internal and external (in)tangible resources (like start-up's teams and external networking) regarding decisions surrounding BSS. Additionally, entrepreneurial behavior has also been recognized as an essential element of the decision process when BSS use is being considered (Gartner, 1985, 1989; Gustafsson, 2006).

But, in spite of all of this, very little is known about the specific contribution of entrepreneurs' behavioral inclination that is involved in the decision to employ BSS. Only a handful of studies have theoretically connected BSS use with attitudinal and behavioral elements related to the entrepreneur. Within this small group we find Burke \& Jarratt's paper (2004), which considers the reliance on the self to explain BSS adoption; Audet \& St-Jean's analysis (2007), that explores entrepreneurs' perceptual and attitudinal factors affecting their use of external support; Bennett's (2007), which addresses entrepreneurs' expectations when using BSS; Bennett \& Ramsden's analysis (2007) about entrepreneurs' motivation to involve business associations offering BSS; and Foo's (2010), that 
connects business teams' experience with support that is sought externally. However, to the best of our knowledge, there has not yet been any research that explores the entrepreneur's decision-making process as he or she weighs up whether to hire BSS or not: these processes are still a 'black box'.

In an attempt to complement previous insight into the use of BSS, and gain more understanding of the entrepreneurs' decision-making processes about these types of external services and programs, we have incorporated a behavioral perspective into the traditional resource-based viewpoint. By integrating the behavioral approach in the resource-based conceptual framework, we define a theoretical model for BSS decisions. Unleashed by entrepreneurial internal forces, the model contemplates a multi-stage decision process throughout which internal teams and also external networks play a relevant role. Then we validate the model with a representative sample of entrepreneurs who interact with a regional development agency based in Barcelona, Spain. We finish with a discussion of our findings, and comment on the results and our conclusions in this area of entrepreneurship.

\section{Towards a more holistic picture of the decisions to use BSS}

External BSS are relevant sources of knowledge, expertise and skills (Chrisman, 1999; Chrisman \& McMullan, 2000, 2004; Aldrich \& Ruef, 2006) that the entrepreneur might require when he or she is creating and growing his/her emerging business. They can enhance a new firm's strategic decision-making (Bennett \& Ramsden, 2007), improve a firm's strategy implementation (Van den Ven et al., 1984; Roper \& Hewitt-Dundas, 2001), or resolve organizational issues (Chrisman \& Leslie, 1989; Chrisman \& McMullan, 2000). Among other advantages, BSS contribute to building a firm's capabilities (Mole \& Keogh, 2009). Far from designing and offering a unique BSS mode that might meet an entrepreneur's particular needs (O'Farrell \& Moffat, 1991; Fitzsimmons, Noh \& Thies, 1998), BSS suppliers often provide a range of support services that include: services related to physical facilities or incubation spaces where the new organization can be based (Hackett \& Dilts, 2004); coaching and counseling services (Abduh, D'Souza, Quazi \& Burley, 2007); networking services that are conceived to foster and offer the opportunity to collaborate with other firms and institutions (Peters, Rice \& Sundararajan, 2004); and additional services - like training and technology support - done through the internet and other new media (Lawless, Allan \& O'Dwyer, 2000; Thomas, Packham, Miller \& Brooksbank, 2004).

Resource-based view presents a theoretical framework to understand the utilization of BSS by entrepreneurs. From this perspective, external networks and contacts, such as scientific-based innovation agents, along with a firm's workforce and the owner's team, offer useful information and (in)tangible resources that help decide whether, or not, to use BSS (Ucbasaran et al., 2003; Lockett, Ucbasaran \&
Butler, 2006). But this approach does not take into consideration either the BSS decision process itself, which remains as something of a black box, nor does it consider the impact of an entrepreneur's internal triggering forces over a BSS decision. Remarkably, consumer behavior and managerial decision-making theories (Engel, Kollat \& Blackwell, 1968; Howard \& Sheth, 1969) can provide a new perspective on this issue. Within this behavioral conceptual framework, the decision to use BSS is conceived as the result of a multi-stage process, let loose by the individual's motivation and previous experience, and throughout which he or she searches for and evaluates information about alternate services before making a decision (Hong \& Sternthal, 2010; Kuskov \& Villas-Boas, 2010; Mehta, Hoegg \& Chakravarti, 2011).

Following the reasoning of these approaches, entrepreneurs are acknowledged as potential BSS users (Rice, 2002). They are influenced by forces that drive them from within, and they go through a decision-making process that tells them whether to use BSS - or not. Additionally, due to the complexity of BSS, plus the importance of these services when a new firm faces difficulties, BSS decisions make necessary the earlier development of searches for understanding what BSS are available (as seen in Figure 1). And yet influenced by the information and other (in)tangible resources provided by external networks and the start-up's team, this multi-stage sequence is born out of an entrepreneur's internal triggering force related to the entrepreneurs' own motivations or previous experiences (Hills \& LaForge, 1992; Gardner, 1994; Hansen \& Eggers, 2010).

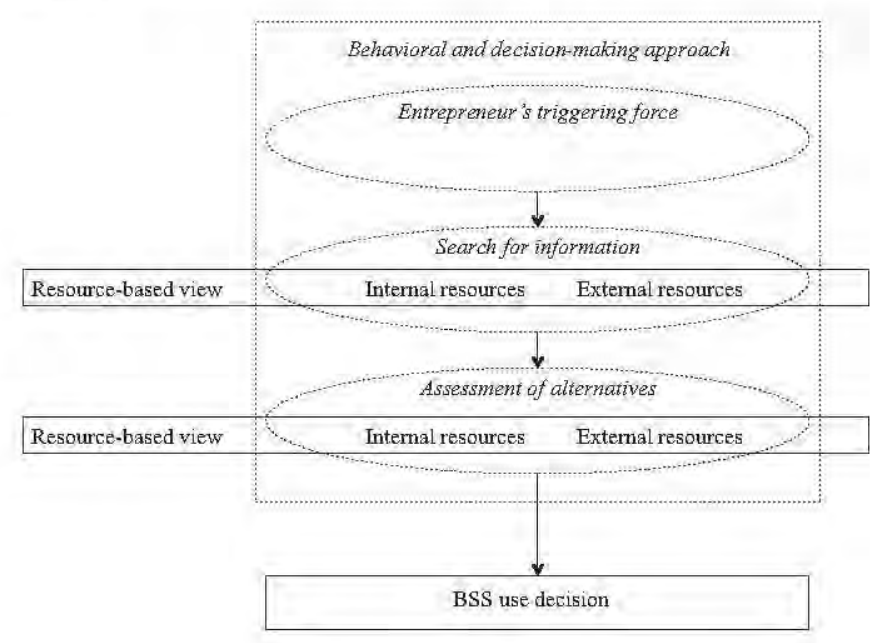

Figure 1: Integrative framework for BSS use decisions

\section{Internal triggering forces}

Behavioral research on BSS use decisions has underlined how personal experience triggers motivated individuals through decision-making processes (e.g. Hoch \& Deighton, 1989; Yalch \& Brunel, 1996), in order to satisfy their particular needs. Not surprisingly, an entrepreneur's previous experience of creating a business has been revealed to be a key element that influences decisions for start-ups 
(Kets de Vries, 1977; Brockhaus, 1982; Westhead, Ucbasaran \& Wright, 2009).

But the direction of the influence of prior experiences of searching for information has not been clarified, and only a few findings show that those entrepreneurs with little or no prior knowledge of BSS, or who are less familiar with BSS, might do fewer or simpler searches (Westhead, Ucbasaran \& Wright, 2005; Gustafsson, 2006). Despite the scarcity of evidence, it seems reasonable to presume that entrepreneurs with greater experience will better understand information mechanisms, of all kinds, that are geared to the creation of a start-up (e.g. procedures to exploit internal information, and external entities who find information about potentially beneficial BSS). So more experienced entrepreneurs may bear lower search costs (Punj \& Staelin, 1983; Alba \& Hutchinson, 1987) and be more likely to engage in exhaustive searches (Westhead et al., 2009). According to this line of reasoning, it is likely that an entrepreneur's prior experience helps in collecting information within the organization (Fiet, Piskunov \& Patel, 2005; Fiet, Norton \& Van Clouse, 2007) and exploring external information resources (Cooper, Folta \& Woo, 1995; Westhead et al, 2005), as stated in the following hypotheses:

\section{H11 Prior start-up experience positively influences internal information search}

\section{H12 Prior start-up experience positively influences external information search}

\section{Information search and assessment}

Following the rationale of user behavior in decision-making (Punj \& Staelin, 1983; Johnson \& Russo, 1984; Brucks, 1985), the flow of information about alternate BSS that might potentially deliver support to the start-up, can come from either internal or external sources. In any case, the assessment of this information can become a complex and resource-demanding activity (Gómez \& Sánchez, 2005; Tihula, Huovinen \& Fink, 2009), which requires the involyement of both internal and external agents. More precisely, the specificities and intricacies of the assessment of the information gathered - whether externally or internally - might require the involvement of all of the owners in the start-up's team (Kor \& Mahoney, 2000; Ucbasaran et al., 2003). Similarly, internal and external searches can imply a greater willingness to cooperate with scientific-based agents (Kleinknecht \& Reijnen, 1992; Fritsch \& Lukas, 2001; Tether, 2002; López, 2008), like universities and research centers, who can specifically assist with the acquisition of advanced knowledge (Belderbos, Carree, Diederen, Lokshin \& Veugelers, 2004; Laursen \& Salter, 2004).

Once involved in the assessment of the set of BSS available, the start-up's owner team can work with professional contacts (Cooper et al., 1995; Westhead et al., 2005) that facilitate collaboration with relevant "close agents", those agents that are found in the new firm's specific microenvironment (such as technology suppliers, consultants, industry-firm associations, and financial entities) to assess specific pieces of information about BSS (Cooper et al., 1995; Tether, 2002; Belderbos et al,, 2004). In addition, and as research in inter-firm collaboration suggests, collaborative relationships with close agents in the microenvironment can continue to facilitate and pinpoint specific areas of cooperation when information is assessed with agents in scientific fields (Fritsch \& Lukas, 2001). This is due to the usual perception of cooperative business relationships as complementary, rather than substitutive (Das \& Teng, 2000; Bönte \& Keilbach, 2005), and thus the willingness of firms already involved in collaborative activities to expand their current cooperative links with agents who might not be quite so near to hand, such as scientific-based institutions (Laursen \& Salter, 2004). All of this leads to the following set of hypotheses:

\section{H21 Internal information flows positively influence the participation of the start-up's owner team in information assessment}
H22 External information flows positively influence the participation of the start-up's owner team in information assessment
H31 Internal information flows positively influence cooperation with scientific-based agents in information assessment

\section{H32 External information flows positively influence cooperation with scientific-based agents in information assessment}

H4 Owner team participation in the decision process positively influences cooperation with agents within the microenvironment in information assessment

H5 Cooperation with agents of the microenvironment in the decision process positively influences cooperation with scientific-based agents in information assessment

\section{BSS use decisions}

According to the decision-making rationale, the use of gathered information to assess the set of BSS available (Casson, 2005) may culminate in choosing the potentially best alternative taken into consideration, and utilizing it. However, as start-up's owner teams who are more involved in BSS decision-processes can provide the firm with relevant knowledge and (in)tangible resources for startingup (Lubatkin, Simsek, Ling \& Veiga, 2006), a substitution effect (Chandler \& Hanks, 1998; Das \& Teng, 2000) between the entrepreneurial owner team's participation, within the decision process, and the use of external BSS is expected.

Collaborating with scientific-based agents in evaluating alternative BSS can facilitate the assimilation of new knowledge about these external resources (Cohen \& 
Levinthal, 1980, 1990; Belderbos et al., 2004). Eventually, the specialized knowledge provided by scientific-based agents may push forward the decision to use BSS, as it allows the entrepreneur to better define the set of alternate BSS to take into consideration and also to apply evaluative criteria to assess them - which in turn makes it easier to adopt subsequent decisions related to using BSS.

H6 Start-up's owner team's participation in the decision process negatively influences BSS use decisions

H7 Cooperation with scientific-based agents in information assessment positively influences BSS use decisions

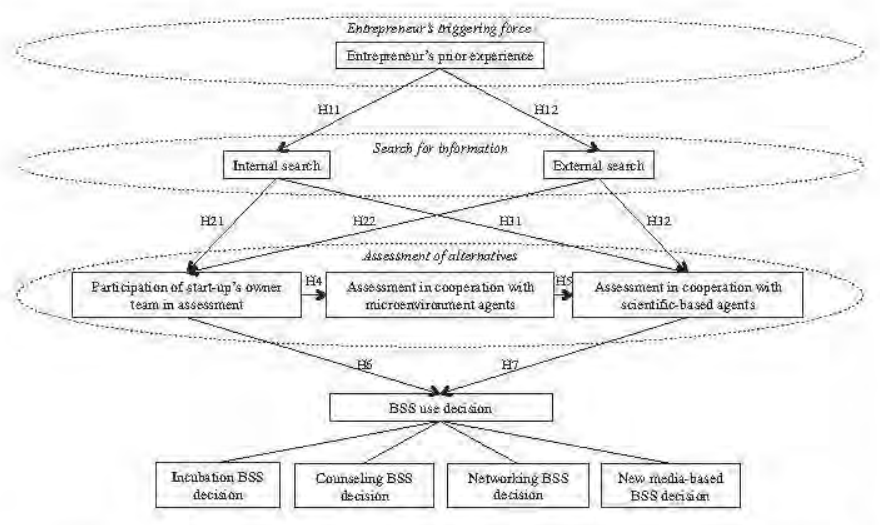

Figure 2: Theoretical model of BSS use decision process

\section{Methodology}

\section{Scenario and data}

A survey was launched in the universe of entrepreneurs (256 in total) who interact with a public development agency based in Barcelona, Spain, that serves the metropolitan region of Barcelona (Castells \& Vilaseca, 2006). The agency, named Barcelona Activa, aims to promote the creation of new firms and helps with their consolidation by means of a wide spectrum of programs, services and activities, including an incubation center. Founded in 1986, this institution has become a reference, within the OECD area, in fostering business projects and promoting imnovation to such an extent that it has become a role model for other institutions that promote entrepreneurship (Barcelona Activa, 2012). In fact, some of the brand new BSS created by Barcelona Activa have been later adapted and offered by analogous institutions (OECD, 2009).

Data was gathered between July 2005 and January 2006. During the first three months of that period, an online survey was sent out, along with two reminders to participate in the survey. Then a paper questionnaire was physically distributed to those entrepreneurs who had not filled in the online questionnaire. With a total response rate of $52.4 \%$, a representative sample of 136 entrepreneurs was collected. After questionnaires were eliminated that did not have answers, the complete model was run using the data from 126 observations.

\section{Measurements}

The constructs and measurements used in the survey were adapted from those validated in previous relevant research, or developed on the basis of the literature review and two focus groups, one of which was with entrepreneurs and the other with institutional staff.

To measure the entrepreneur's previous experience, we considered whether the entrepreneur had already created a firm or not (e.g. Peña, 2002; Haynes, 2003). So we used a dichotomous variable that is zero $(0)$ for entrepreneurs with no prior start-up experience and one (1) for those with at least some experience. The measurement of the external information search about potential BSS that could be used was based on Katila's (2002) number of information channels explored. Therefore, external search is an additive variable that reflects the number of external sources consulted, and ranges from zero ( 0 sources) to six (6 or more sources). Similarly, internal information search on BSS was measured through the number of full-time employees involved in searching internal information (Fariñas \& López, 2006; Elche-Hotelano, 2011). This variable ranges from zero ( 0 employees) to six ( 6 or more employees). The participation of the owner team in the assessment of information was captured by means of the number of the start-up's owners involved (Ucbasaran et al., 2003; Dautzenberg \& Reger, 2010). The variable ranges from one to four, where four represents 4 or more owners. Cooperation with agents of the microenvironment in assessment activities was measured with an additive variable that expresses the number of different relations (Katila, 2002; Becker \& Dietz, 2004) established for information assessment purposes with those agents (competitors, distributors, clients, technology suppliers and other suppliers). The variable ranges from zero ( 0 relations established) to five (relations established with 5 different types of microenvironment agents).

Analogously to Fernández-Ardèyol and Lladós-Masllorens (2011), scientific-based cooperation of the information assessment about BSS was measured by means of an additive variable that captures the intensity of those collaborative relationships with universities and other research centers. The variable ranges from zero (no collaborative relationship) to two (links to both universities and other research centers).

In order to capture the decision about BSS use, we modeled a latent variable, which we measure via four additive indicators. Each of these indicators reflects the degree of utilization of the four types of BSS previously identified: incubation BSS; coaching and counseling BSS; networking BSS; and new media-based BSS. Incubation scale labels range from zero (no participation in any activity or program conforming incubation BSS) to six (having taken part in 6 activities/programs of this category). Similarly, the variable that reflects BSS use of coaching and counseling ranges from zero (no participation in any activity or program of this category) to three; and using BSS for networking ranges 
from one to two (where 2 represents the maximum number of activities/programs in this category in which the entrepreneur has taken part). New media-based BSS range from zero to seven ( 7 being the maximum number of new media-based BSS in which the entrepreneur has participated).

We have measured the construct validity of the unobserved latent variable by means of a principal components analysis (Nunnally \& Bernstein, 1994) with varimax rotation. The resulting factor, which explains $69.6 \%$ of the variance, has an eigenvalue (2.784) clearly greater than 1 . We have further tested the reliability of this measure through the Cronbach alpha coefficient, which takes a value $(0.782)$ higher than the threshold of 0.70 (Hair, Black, Babin \& Anderson, 2010).

\section{Model estimation and results}

In order to test the various levels of causation and the interrelations among the variables considered, we have analyzed a general nonlinear structural equation model. Structural equation models are regression models with observed and latent variables (Lee, 2007) that explain multiple interrelations among variables (Hair et al., 2010). Due to the ordinal and interval nature of the variables taken into consideration (Albert \& Chib, 1993; Lee \& Song, 2003), we have used a Bayesian approach to estimate the parameters of the model. By means of Markov chains and Monte Carlo methods, Bayesian estimation also allows sample replication, making it especially appropriate and reliable for relatively small samples (Lee, 2007: 5), like this available here.

To examine the adequacy of the model in terms of statistical convergence, we have used Gelman and Rubin's (1992) potential scale reduction method - which compares the variance between and within Markov chains for the last $n$ values from each chain - along with the analysis of posterior distribution graphics (not shown here for the sake of space). We have verified the model's goodness of fit and adequacy by means of the posterior predictive $p$-value (Gelman, Meng \& Stern, 1996). And we have employed Bayesian credible intervals to test whether the estimated parameters of critical paths are significantly different from zero.

The model first converged with 5,501 iterations and, as recommended by Gelman et al. (1996), yielded a posterior $p$-value $(0.49)$ not far from 0.50 (Lee, 2007: 129). But as the positive relation $(0.124)$ between the previous start-up experience (PrExp) and the external information flows (EIF), as well as between EIF and owners" team participation (Team) $(0.129)$, neither was significantly different from 0 , so these two paths have been removed. After 4,647 iterations, convergence of the revised model parameters is reached, as well as the model's goodness of fit and adequacy (being 0.45 the Bayesian posterior $p$-value). Results are shown in Figure 3 (which includes direct standardized effects) and Table 2 (for the total standardized effects).

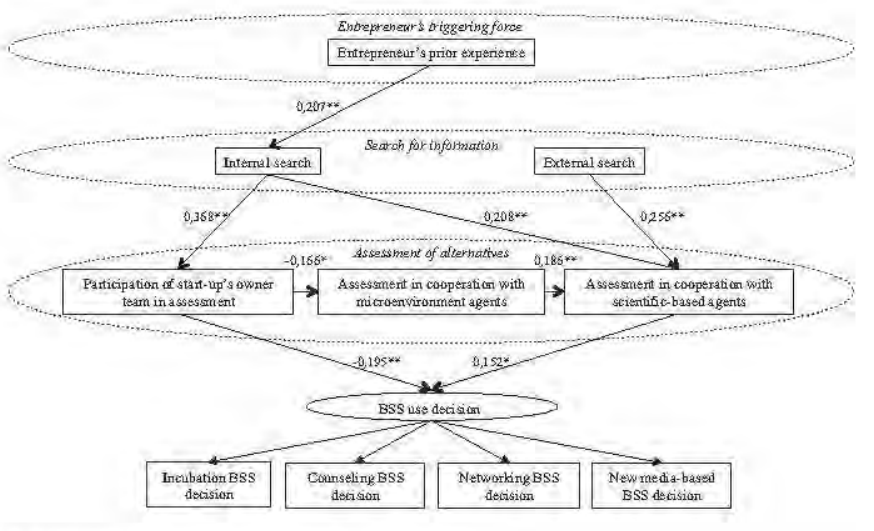

* Estimated parameters significant at 90\%

**Estimated parameters significant at $95 \%$

\section{Figure 3: Parameter estimates for the analytical model}

Since the path parameter linking previous start-up experience and internal search is positive and significantly different from zero $(0.207)$, H11 is confirmed. By contrast, the relationship between PrExp and EIF (H12) is not supported. Moreover, the positive sign of total standardized effects, measuring the influence of PrExp on both Team $(0.076)$ and scientific cooperation in the decision process (ScCoop) (0.041), allows confirming the positive impact of PrExp on the assessment of alternative BSS when it is mediated by internal information flows (IIF). However, no total effect significantly different from zero has been detected for PrEXp with the latent variable capturing the entrepreneur's decision about BSS use (UseDec), nor from PrEXp with the use of any type of BSS.

Table 2: Total standardized effects

\begin{tabular}{|c|c|c|c|c|c|c|c|}
\hline & PrExp & IIF & Team & EIF & MiCoop & ScCoop & UseDec \\
\hline IIF & $0.207 * *$ & 0.000 & 0.000 & 0.000 & 0.000 & 0.000 & 0.000 \\
\hline Team & $0.076 * *$ & $0.368 * *$ & 0.000 & 0.000 & 0.000 & 0.000 & 0.000 \\
\hline MiCoop & -0.013 & $-0.061 *$ & $-0.166^{*}$ & 0.000 & 0.000 & 0.000 & 0.000 \\
\hline ScCoop & $0.041 * *$ & $0.196 * *$ & -0.031 & $0.256 * *$ & $0.186 * *$ & 0.000 & 0.000 \\
\hline UseDec & -0.009 & -0.041 & $-0.199 * *$ & $0.039 *$ & $0.028 * *$ & $0.152 *$ & 0.000 \\
\hline Incubator & -0.008 & -0.038 & $-0.185 * *$ & $0.036 *$ & $0.026 * *$ & $0.141 *$ & $0.927 * *$ \\
\hline Counseling & -0.004 & -0.021 & $-0.101 * *$ & $0.020^{*}$ & $0.014 * *$ & $0.077^{*}$ & $0.504 * *$ \\
\hline Networking & -0.006 & -0.027 & $-0.130 * *$ & $0.026 *$ & $0.019 * *$ & $0.100^{*}$ & $0.650 * *$ \\
\hline New media & -0.009 & -0.040 & $-0.194 * *$ & $0.038 *$ & $0.028 * *$ & $0.148 *$ & $0.971 * *$ \\
\hline
\end{tabular}

**Values significant at $95 \%$

* Values significant at $90 \%$ 
As the positive path parameter linking PrExp and EIF is not significantly different from zero, it is not possible to determine whether an external information search acts as an antecedent of activities related to the assessment of alternatives (owners' team participation, cooperation with microenvironment agents and scientific-based cooperation). However, the path parameter between EIF and ScCoop $(0.256)$ is positive and significantly different from zero, supporting H32. EIF also positively affects the decision to use BSS when mediated by ScCoop. For its part, IIF positively and directly affects ScCoop (0.196). In addition, this influence is indirectly mediated by Team and collaboration with agents of marketing microenvironment (MiCoop). Despite that the indirect effects are not significantly different from zero, the total effects are. As a consequence, the hypothesis $\mathrm{H} 31$ is validated. And, as expected, the parameter linking IIF and Team is positive and significantly different from zero (H21). By contrast, the influence of EIF on Team is not statistically significant, leading us to reject $\mathrm{H} 22$.

Contrary to the expected direction, results show a negative sign of the parameter connecting Team with MiCoop ($0.166)$, refuting $\mathrm{H} 4$, as well as a negative total effect of the IIF onto MiCoop for BSS decisions (-0.061). By contrast, the corresponding parameter linking MiCoop and ScCoop $(0.186)$ is positive and significantly different from zero, confirming H5, Further, MiCoop positively influences BSS use decision when mediated by ScCoop. And since the parameter corresponding to the influence of Team participation on the BSS use decision is significantly different from zero, and negative, $\mathrm{H} 6$ is also verified. The same happens when considering the path between ScCoop and BSS use decisions, although here the sign is positive, as it was presumed $(\mathrm{H} 7)$.

\section{Discussion and concluding remarks}

In this study, we situate entrepreneurs and their freedom of choice at the very center of the decision processes that culminate with the use of BSS - those services and programs that are particularly oriented to provide support to entrepreneurial initiatives. In an attempt to offer further insights into how and what entrepreneurs do in the decision processes to use BSS, we suggest complementing the resource-based conceptual framework (usually employed by studies on BSS in the field of entrepreneurship) with a behavioral and decision-making approach. Within the resulting integrative framework, a decision process is proposed for BSS use.

Initially, a process is triggered by internal factors related to the entrepreneur's personal prior start-up experiences. It then develops throughout two consecutive stages during which internal and external resources play a relevant roll: in the first by providing information about alternate, potential BSS; in the second by facilitating the assessment of them. The process ends up with the effective decision of using a BSS.
As predicted, entrepreneurs' decisions about BSS portray themselves to be complex and reflexive: unlike typically simplistic and short decision-making processes driven by unplanned behavior, BSS decisions require high involvement from the entrepreneur, and evolve throughout the four differentiated phases previously identified (i.e. entrepreneur's triggering force, information search, alternative assessment, and BSS use decision). This provides support to our holistic view of entrepreneurs' decisions about BSS and shows, for the first time in the entrepreneurship literature, the appropriateness of a multistage framework to help deconstruct and predict entrepreneurial behavior with regards to the use of BSS.

Apart from this contribution, the empirical test undertaken also answers the call of some researchers in the field (Gustafsson, 2006; Baron, 2007). As a matter of fact, our results reveal entrepreneurs' cognitive factoring gained from prior similar experiences during the creation of a start-up, and which have to do with the familiarity and confidence of the BSS decision processes, that acts as a triggering force within entrepreneurs' decision-making behavior. More specifically, entrepreneurs' prior experiences of BSS-related activities are shown to prompt their willingness to gather informational resources about potentially useful BSS from within the organization. By contrast, and contrary to our expectations and those found by Westhead et al. (2005) and Gordon, Davidsson \& Steffens (2009), entrepreneurs' familiarity and confidence with BSS that have been provided by experience do not directly encourage the search for information in external sources. Therefore it seems that experienced entrepreneurs do not consider it so necessary to resort to a wide spectrum of external information sources, which is indeed in line with findings gathered by Westhead et al. (2005). Nevertheless, the undertaking of an external information search, along with the search within internal sources, turns out to be a key activity in the decision processes for BSS use. As observed, and in accord with Fritsch \& Lukas's (2001), Tether's (2002) and López's (2008), both types of searches (i.e. external and internal) determine the cooperation with scientific-based agents for BSS evaluating purposes, and this then opens up the decisions about BSS utilization. And so the knowledge and resources acquired thanks to the cooperation with scientificbased agents allows entrepreneurs to better identify business opportunities and evaluate those BSS that they could benefit from the most: ultimately this leads to the adoption of the corresponding BSS.

A booster of external cooperation with assessment purposes as external search is, it might be less of a drain on internal resources. This is because, unlike an internal search, it does not lead to the entire owners' team having to participate in assessing the information collected. For its part, diverse and concrete effects derive from the participation of the owners' team in the decision-making process. On the one hand, the undertaking of information search within the organization stimulates the involvement of the entire owner's team to assess it. And interestingly, the knowledge and resources provided by them turn out to be a substitute of those that would be obtained from external support services and 
programs; so the owner team participation might eventually reduce the entrepreneur's willingness to use BSS, which is in harmony with Chandler \& Hanks (1998) view of founders" role in emerging businesses. On the other hand, the owner's team participation indirectly affects BSS decisions because it discourages collaboration for assessment purposes with agents in the microenvironment. Again, this result suggests that when the owner's team is part of the decision-making process, it can heighten the relevant capabilities and expertise they might provide, which could reduce the new firm's need of collaborating with external agents who come from the microenvironment.

Our investigation also highlights evidence of the complementary effects of inter-firm collaboration, yet now within the context of BSS adoption. Similarly to some studies on strategic cooperation (Das \& Teng, 2000; Belderbos et al., 2004; Bönte \& Keilbach, 2005), we found that, once external cooperation is established with close agents of the firm's specific environment, firms are more willing to grow their collaboration network with organizations, like scientific-based agents, that are not necessary to hand.

These insights not only offer an important backdrop for understanding entrepreneurial decisions regarding BSS use, but they also have relevant implications for policy makers, business incubators, and other public and private institutions that provide BSS. As a matter of fact, BSS providers can offer relevant information about their range of services and programs to their potential users as much as to other relevant key agents in the use of the decision-making process - such as scientific-based institutions and organizations within the new firm's microenvironment. BSS providers should equip those agents with informational resources and tools that allow them to deliver the appropriate help to entrepreneurs in their decision-making processes regarding BSS. This recommendation is particularly important when it comes to making BSS use decisions easier for entrepreneurs with little or no start-up experience, as they are, paradoxically, less likely to gather comprehensive information about BSS and therefore only carry out limited decision processes about BSS.

Our research not only shows that BSS decisions involve multi-step and selective processes but also that these processes are highly influenced by entrepreneurs' prior experience and knowledge. This suggests that there is not a single recipe for success of entrepreneurship policies in the modern knowledge economy. By the same token that entrepreneurs create new organizations adapted to the transformational changes of labor and product markets, the design and development of BSS should adapt to the changing and different motivations and needs of entrepreneurs.

This investigation, however, is not exempt from limitations. As with many other studies on BSS, sample data has been collected from entrepreneurs linked to only one institution. Furthermore, it is recommended that future studies consider entrepreneurs 'behavior in BSS post-usage stages. It would be relevant to do an in-depth study of prior experience in firm creation, and also explore possible different BSS decision-making behaviors among experienced serial entrepreneurs (who have sequentially created various firms) and experienced portfolio entrepreneurs (who simultaneously own multiple firms). In addition, the present research might be extended beyond a general analysis of entrepreneurs' decisions on BSS use to its modeling for decisions on particular BSS services and programs. Last but not least, it would be worthwhile to regard the specific role of each type of external agent with whom the new firm cooperates within BSS decision-making processes.

\section{Acknowledgements and disclaimer}

This work has been partially supported by Barcelona Activa; and the European Commission (reference no. 2013-1-PT1LEO05-15504 of the Lifelong Learning Program).

This publication reflects the views only of the authors, and the Commission cannot be held responsible for any use which may be made of the information contained therein.

\section{References}

Abduh, M., D’Souza, C., Quazi, A. \& Burley, H.T. 2007. 'Investigation and classifying clients' satisfaction with business incubator services;, Managing Service Quality, 17(1): 74-91.

Adler, P.S. \& Kwon, S-W. 2002. 'Social capital: Prospects for a new concept", Academy of Management Review, 27(1): $17-40$.

Alba, J.W. \& Hutchinson, J.W. 1987. 'Dimensions of consumer expertise', Journal of Consumer Research, 13(4): 411-54.

Albert, J.H. \& Chib, S. 1993. 'Bayesian analysis of binary and polychotomous response data', Journal of the American Statistical Association, 88(422): 669-79.

Aldrich, H.E. \& Ruef, M. 2006. Organizations evolving. 2nd edition. London: Sage.

Audet, J. \& St-Jean, E. 2007. 'Factors affecting the use of public support services by SME owners: Evidence from a periphery region of Canada', Journal of Developmental Entrepreneurship, 12(2): 165-80.

Barcelona Activa. 2012. Report on activities 2011. Barcelona: Barcelona Activa.

Baron, R.A. 2007. Behavioral and cognitive factors in entrepreneurship: Entrepreneurs as the active element in new venture creation', Strategic Entrepreneurship Journal, 1(1/2): $167-82$. 
Becker, W. \& Dietz, J. 2004. 'R\&D cooperation and innovation activities of firms-evidence for the German manufacturing industry', Research Policy, 33(2): 209-23.

Belderbos, R., Carree, M., Diederen, B., Lokshin, B. \& Veugelers, R. 2004. 'Heterogeneity in R\&D cooperation strategies', International Journal of Industrial Organization, 22(8/9): 1,237-63.

Bennett, R.J. 2007. 'Expectations-based evaluation of SME advice and consultancy: An example of business link services', Journal of Small Business and Enterprise Development, 14(3): 435-57.

Bennett, R.J, \& Ramsden, M. 2007. 'The contribution of business associations to SMEs: Strategy, bundling or reassurance?', International Small Business Journal, 25(1): 49-76.

Bönte, W. \& Keilbach, M. 2005. 'Concubinage or marriage? Informal and formal cooperations for innovation', International Journal of Industrial Organization, 23(3/4): 279-302.

Brockhaus, R.H. 1982. 'The psychology of the entrepreneur'. In Kent, C.A., Sexton, D.L. \& Vesper, K.H. (Eds.). Encyclopedia of entrepreneurship. Englewood Cliffs, New Jersey: Prentice Hall.

Brucks, M. 1985. 'The effects of product class knowledge on information search behavior', Joumal of Consumer Research, 12(1): 1-16.

Burke, G.I. \& Jarratt, D.J. 2004. "The influence of information and advice on competitive strategy definition in small and medium-sized enterprises', Qualitative Market Research: An International Journal, 7(2): 126-38.

Casson, M. 2005. 'Entrepreneurship and the theory of the firm', Journal of Economic Behavior \& Organization, 58(2): $327-48$.

Castells, M. \& Vilaseca J. (Eds.), Lladós, J. (Coord.), Ammetller, G., Esteban, I., Fernández, M., Rodríguez, I. \& Torrent, J. 2007. Entorno innovador, iniciativa emprendedora y desarrollo local. Barcelona: Octaedro.

Chandler, G.N. \& Hanks, S.H. 1998. "An examination of the substitutability of founders human and financial capital in emerging business ventures', Journal of Business Venturing, 13(5): 353-69.

Chrisman, J.J. 1999. 'The influence of outside-generated knowledge resources on venture creation', Journal of Small Business Management, 37(4): 42-58.

Chrisman, J.J. \& Leslie, J. 1989. 'Strategic administrative and operating problems: The impact of outsiders on small firm performance', Entrepreneurship Theory \& Practice, 13(3): $37-51$.
Chrisman, J.J. \& McMullan, W.E. 2004. 'Outsider assistance as a knowledge resource for new venture survival', Journal of Small Business Management, 42(3): 229-44.

Chrisman, J.J. \& McMullan, W.E. 2000. 'A preliminary assessment of outsider assistance as a knowledge resource: The longer-term impact of new venture counseling?, Entrepreneurship Theory \& Practice, 24(3): 37-53.

Cohen, W.M. \& Levinthal, D.A. 1990. 'Absorptive capacity: A new perspective on learning and innovation', Administrative Science Quarterly, 35(1): 128-52.

Cohen, W.M. \& Levinthal, D.A. 1989. 'Innovation and learning: The two faces of R\&D', The Economic Journal, 99(397): 569-96.

Cooper, A.C., Folta, T.B. \& Woo, C.Y. 1995. 'Entrepreneurial information search', Journal of Business Venturing, 10(2): 107-20.

Das, T.K. \& Teng, B-S. 2000. 'A resource-based theory of strategic alliances', Journal of Management, 26(1): 31-61.

Dautzenberg, K. \& Reger, G. 2010. 'Entrepreneurial team characteristics and success of new technology-based firms in Germany', International Journal of Business and Globalisation, 4(1): $71-94$.

Dyer, L.M. \& Ross, C.A. 2008. 'Seeking advice in a dynamic and complex business environment: Impact on the success of small firms', Journal of Developmental Entrepreneurship, 13(2): 133-49.

Elche-Hotelano, D. 2011. 'Sources of knowledge, investments and appropriability as determinants of innovation: An empirical study in service firms', Innovation: Management, Policy \& Practice, 13(2): 220-35.

Engel, J.F., Kollat, D.T. \& Blackwell, R.D. 1968. Consumer behavior. New York: Holt, Rinehart and Winston.

Fariñas, J.C. \& López, A. 2006. Las empresas pequeñas de base tecnológica en España: Delimitación, evolución y características. Madrid: Dirección General de Política de la PYME.

Fernández-Ardèvol, M. \& Lladós-Masllorens, J. 2011. 'Determinants of science-based cooperation: Evidence in a simple of small and micro firms', Managing Global Transitions, 9(4): 319-33.

Fiet, J.O., Norton, W.I., Jr. \& Van Clouse, G.H. 2007. 'Systematic search as a source of technical innovation: An empirical test', Journal of Engineering and Technology Management, 24(4): 329-46.

Fiet, J.O., Piskunov, A. \& Patel, P.C. 2005. 'Still searching (systematically) for entrepreneurial discoveries', Small Business Economics, 25(5): 489-504. 
Fitzsimmons, J.A., Nòh, J. \& Thies, E. 1998. 'Purchasing business services', Journal of Business \& Industrial Marketing, $13(4 / 5): 370-80$.

Foo, M-D. 2010. "Member experience, use of external assistance and evaluation of business ideas', Journal of Small Business Management, 48(1): 32-43.

Fritsch, M. \& Lukas, R. 2001. 'Who cooperates on R\&D?', Research Policy, 30(2): 297-312.

Gardner, D.M. 1994. 'Marketing/entrepreneurship interface: A conceptualization'. In Hills, G.E. (Ed.). Marketing and entrepreneurship: Research ideas and opportunities. Westport, Connecticut: Quorum Books.

Gartner, W,B. 1989. "Who is an entrepreneur?" Is the wrong question', Entrepreneurship Theory \& Practice, $13(4)$ : 47-68.

Gartner, W.B. 1985, 'A conceptual framework for describing the phenomenon of new venture creation', Academy of Management Review, 10(4): 696-706.

Gelman, A., Meng, X-L. \& Stern, H. 1996. 'Posterior predictive assessment of model fitness via realized discrepancies', Statistica Sinica, 6(4): 733-60.

Gelman, A. \& Rubin, D.B. 1992. 'Inference from iterative simulation using multiple sequences', Statistical Science, $7(4): 457-72$.

Gómez, C. \& Sánchez, J.I. 2005. 'Human resource control in MNCs: A study of the factors influencing the use of formal and informal control mechanisms', The International Journal of Human Resource Management, 16(10): 1,847-61.

Gooderham, P.N., Tobiassen, A., Doving, E. \& Nordhaug, O. 2004. 'Accountants as sources of business advice for small firms', International Small Business Joumal, 22(1): 5 22.

Gordon, S., Davidsson, P. \& Steffens, P. 2009. 'Novice vs. habitual entrepreneurship: Differences in motivations, actions and expectations'. In Proceedings of the $6^{\text {th }}$ Australian Graduate School of Entrepreneurship (AGSE) International Entrepreneurship Research Exchange. Adelaida: 4-6 February.

Gustafsson, V. 2006. Entrepreneurial decision making: Individuals, tasks and cognitions. Cheltenham, United Kingdom: Edward Elgar.

Hackett, S.M. \& Dilts, D.M. 2004. 'A real options-driven theory of business incubation', Journal of Technology Transfer, 29(1): 41-54.

Hair, J.F., Jr, Black, W.C., Babin, B.J. \& Anderson, R.E. 2010. Multivariate data analysis. A global perspective $\left(7^{\text {th }}\right.$ Edition). Upper Saddle River, New Jersey: Pearson Prentice Hall.
Hansen, D.J. \& Eggers, F. 2010. 'The marketing/entrepreneurship interface: A report on the "Charleston Summit", Journal of Research in Marketing and Entrepreneurship, 12(1); 42-53.

Haynes, P.J. 2003. 'Differences among entrepreneurs. "Are you experienced?" may be the wrong question", International Journal of Entrepreneurial Behaviour \& Research, 9(3); 111-28.

Hills, G.E. \& LaForge, R.W. 1992. 'Research at the marketing interface to advance entrepreneurship theory', Entrepreneurship Theory \& Practice, 16(3): 33-59.

Hoch, S.J. \& Deighton, J, 1989, 'Managing what consumers learn from experience', Journal of Marketing, 53(2): 1-20.

Hong, J. \& Sternthal, B. 2010. 'The effects of consumer prior knowledge and processing strategies on judgments', Journal of Marketing Research, 47(2): 301-11.

Howard, J.A. \& Sheth, J.N. 1969. The theory of buyer behavior, New York: John Wiley \& Sons.

Johnson, E.J, \& Russo, J.E. 1984. 'Product familiarity and learning new information', Journal of Consumer Research, 11(1): $542-50$.

Katila, R, 2002. 'New product search over time: Past ideas in their time?', Academy of Management Journal, 45(5): $995-1,010$.

Kets de Vries, M.F.R. 1977. 'The entrepreneurial personality. A person at the crossroads". In Westhead, P. \& Wright, M. (Eds.). 2000. Advances in entrepreneurship, 1. Cheltenham: Edward Elgar.

Kleinknecht, A. \& Reijnen, J.O.N. 1992. "Why do firms cooperate on R\&D? An empirical study ${ }^{*}$, Research Policy, 21(4): $347-60$.

Kor, Y.Y. \& Mahoney, J.T. 2000. 'Penrose's resource-based approach: The process and product of research creativity', Journal of Management Studies, 37(1): 109-39.

Kuskov, D. \& Villas-Boas, J.M. 2010. "When more alternatives lead to less choice', Marketing Science, 29(3): $507-24$.

Laursen, K. \& Salter, A. 2004. 'Searching low and high: What types of firms use universities as a source of innovation?', Research Policy, 33(8): 1,201-15.

Lawless, N., Allan, J. \& O'Dwyer, M. 2000. 'Face-to-face or distance training: Two different approaches to motivate SMEs to learn', Education + Training, 42(4/5): 308-16.

Lee, S-Y, 2007. Structural equation modeling: A Bayesian approach. Wiley Series in Probability and Statistics. Chichester: Wiley \& Sons. 
Lee, S-Y. \& Song, X-Y. 2003. 'Bayesian analysis of structural equation models with dichotomous variables', Statistics in Medicine, 22(19): 3,073-88.

Lockett, A., Ucbasaran, D. \& Butler, J. 2006. 'Opening up the investor-investee dyad: Syndicates, teams, and networks", Entrepreneurship Theory and Practice, 30(2): 117-30.

López, A. 2008. 'Determinants for R\&D cooperation: Evidence from Spanish manufacturing firms', International Journal of Industrial Organization, 26(1): 113-36.

Lubatkin, M., Simsek, Z., Ling, Y. \& Veiga, J.F. 2006. Ambidexterity and performance in small-to medium-sized firms: The pivotal role of top management team behavioral integration', Journal of Management, 32(5): 646-72.

Mehta, R., Hoegg, J. \& Chakravarti, A. 2011. 'Knowing too much: Expertise-induced false recall effects in product comparison', Journal of Consumer Research, 38(3): 535-54.

Mole, K.F. \& Bramley, G. 2006. 'Making policy choices in non-financial business support: An international comparison', Environment and Planning C: Government and Policy, 24(6): 885-908.

Mole, K.F. \& Keogh, W. 2009. 'The implications of public sector small business advisers becoming strategic sounding boards: England and Scotland compared', Entrepreneurship \& Regional Development, 21(1): 77-97.

Nunnally, C. \& Bernstein, I. 1994. Psychometric theory. 3rd Edition. New York: McGraw-Hill.

OECD. 2009. Promoting entrepreneurship, employment and business competitiveness. The experience of Barcelona [Local development agency review series]. Paris: OECD Leed Programme.

O'Farrel1, P.N. \& Moffat, L.A.R. 1991. "An interaction model of business service production and consumption", British Journal of Management, 2(4): 205-21.

Peña, I. 2002. 'Intellectual capital and business start-up success ${ }^{\prime}$ Journal of Intellectual Capital, 3(2): 180-98.

Peters, L., Rice, M. \& Sundararajan, M. 2004. 'The role of incubators in the entrepreneurial process", Journal of Technology Transfer, 29(1): 83-91.

Punj, G.N. \& Staelin, R. 1983. 'A model of consumer information search behavior for new automobiles', Journal of Consumer Research, 9(4): 366-80.

Rice, M.P. 2002. 'Co-production of business assistance in business incubators. An exploratory study', Journal of Business Venturing, 17(2): 163-87.

Roper, S. \& Hewitt-Dundas, N. 2001. 'Grant assistance and small firm development in Northern Ireland and the
Republic of Ireland', Scottish Journal of Political Economy, 48(1): 99-117.

Tether, B.S. 2002. 'Who co-operates for innovation, and why: An empirical analysis', Research Policy, 31(6): 94767.

Thomas, B., Packham, G., Miller, C. \& Brooksbank, D. 2004. The use of Web sites for SME innovation and technology support services in Wales', Joumal of Small Business and Enterprise Development, 11(3): 400-7.

Tihula, S., Huovinen, J. \& Fink, M. 2009. 'Entrepreneurial teams vs management teams. Reasons for team formation in small firms', Management Research News, 32(6): 555-66.

Ucbasaran, D., Lockett, A., Wright, M. \& Westhead, P. 2003. 'Entrepreneurial founder teams: Factors associated with member entry and exit", Entrepreneurship Theory \& Practice, 28(2): 107-27.

Van den Ven, A.H., Hudson, R. \& Schroeder, D.M. 1984. 'Designing new business startups: Entrepreneurial, organizational and ecological considerations', Journal of Management, 10(1): 87-107.

Westhead, P. 1995. 'Survival and employment growth contrasts between types of owner-managed high-technology firms', Entrepreneurship Theory \& Practice, 20(1): 5-27.

Westhead, P., Ucbasaran, D. \& Wright, M. 2009. 'Information search and opportunity identification: The importance of prior business ownership experience', International Small Business Journal, 27(6): 659-80.

Westhead, P., Ucbasaran, D. \& Wright, M. 2005. 'Decisions, actions, and performance: Do novice, serial, and portfolio entrepreneurs differ?", Journal of Small Business Management, 43(4): 393-417.

Yalch, R. \& Brunel, F. 1996. 'Need hierarchies in consumer judgments of product designs: Is it time to reconsider Maslow's theory?" In Corfman, K.P. \& Lynch, J.G., Jr. (Eds.). Advances in consumer research, 23. Provo, Utah: Association for Consumer Research. 